\title{
A Formação de Personalidades Éticas: Representações de Si e Moral
}

\author{
Luciene Regina Paulino Tognetta ${ }^{1}$ \\ Universidade Estadual de Campinas e Universidade Estadual de São Paulo \\ Yves de La Taille \\ Universidade de São Paulo
}

\begin{abstract}
RESUMO - O artigo apresenta os estudos de uma investigação atual entre 75 adolescentes de 12 a 15 anos, estudantes de colégios particulares da cidade de Campinas, que tem como principal objetivo constatar a possível correspondência entre os julgamentos morais e as representações que os sujeitos têm de si mesmos. A partir de um questionário, os estudos destacam as representações desses sujeitos e respondem a um questionamento de que teriam um caráter ético ou não e se corresponderiam a seus julgamentos morais. Os resultados apontam para uma correspondência entre aqueles cujas representações de si são caracterizadas por conteúdos éticos e julgamentos mais evoluídos quanto à sensibilidade aos sentimentos dos personagens envolvidos nas situações descritas. Tais estudos validam a intenção deste artigo de discutir as correspondências entre ética (como o sujeito se vê) e moral (como julga as situações morais).
\end{abstract}

Palavras-chave: ética; moral; generosidade; emoções; representações de si.

\section{The Formation of Ethical Personalities: Self Representations and Moral}

\begin{abstract}
The article presents studies of a current investigation among 75 adolescents from 12 to 15 years old, students of private schools of Campinas city, that have as main objective to notice a possible correspondence among the moral judgments and the representation that individuals have about themselves. From a questionnaire, the studies bring out the representations of these individuals and answer a questioning if they would have an ethical character or not and if these individuals would correspond to their moral judgments. The results point out to a correspondence among those whose self representations are characterized by more evolved ethical contents and judgments related to sensitivity and to the characters feelings involved in the situations described. Such studies validate the intention of this article to discuss the correspondences between ethics (how the individual sees himself/herself) and moral (how he/she judges the situations moral).
\end{abstract}

Key words: ethics; moral; generosity; emotions; self representation.

A presente pesquisa visou a testar a seguinte hipótese: há uma relação entre os valores éticos associados às representações de si e a qualidade das avaliações morais. Antes de apresentarmos o método e nossos dados, devemos definir os termos empregados na hipótese e apresentar o quadro teórico no qual ela se insere.

Comecemos pelos conceitos "moral" e "ética". Ambos costumam ser, no cotidiano, empregados como sinônimos e referir-se a um conjunto de regras e princípios que configuram deveres. Por exemplo, quando se clama por ética na política está-se exigindo que os políticos obedeçam a regras como "não roubar", "não mentir", "ser justo", regras essas que poderiam ser perfeitamente chamadas de moral. Se o emprego do termo "ética" é, hoje em dia, mais freqüente que o uso do termo "moral", isso se deve certamente apenas ao fato de as referências à ética soarem como mais sofisticadas e liberais, enquanto as referências à moral soariam mais autoritárias e "moralistas". Mas como bem o aponta Blondel (2000): "esse termo (ética), que tem ganhado uma importância cada vez maior, veio aliviar o inextricável embaraço daqueles que desejavam falar de moral sem ousar pronunciar a palavra" (p. 149). A sinonímia dos dois referidos conceitos é, portanto, perfeitamente aceitável. Todavia, é possível, por convenção,

1 Endereço: Av. Florindo Cibin, 1532, apto. 13 bloco 1, Vila Jones , Americana, SP, Brasil 13465-560. E-mail: 1rpaulino@uol.com.br dar-lhes sentidos diferentes e complementares. A convenção mais usual é empregar a palavra "moral" para se referir ao fato e a palavra "ética" para nomear as reflexões e estudos sobre esse fato: quais seriam os fundamentos das regras, dos valores, qual seria a história dos sistemas morais adotados ao longo do tempo, que relações existem entre variáveis sociológicas e os deveres, quais são os processos psicológicos que presidem a legitimação das regras, princípios e valores morais, etc.?

Quanto a nós, vamos assumir uma outra convenção, que se encontra em autores como Paul Ricoeur (1990), Williams (1990), Tugendhat (1999) e Comte-Sponville (1999). Tal convenção define moral como referente aos deveres e ética como referente à "vida boa". Logo, a pergunta moral é "como devo agir?" E a pergunta ética “que vida eu quero viver?" Se a primeira dessas questões indica, portanto, um sentimento de obrigatoriedade, a segunda aponta um sentido para a vida. Antes de prosseguir, devemos esclarecer os conteúdos que vamos associar à moral e à ética. Comecemos pela moral.

Com efeito, variados são os deveres morais existentes. Por exemplo, é certo que os terroristas que derrubaram as Torres Gêmeas Americanas no fatídico dia 11 de setembro de 2001, agiram inspirados pelo dever: o de matar ímpios e inimigos. Mas tal conteúdo associado aos deveres não é, claro, universal, sendo até mais freqüiente acontecer o inverso e se legitimar o mandamento "não matar". Para nós, os conteúdos “justiça”, "dignida- 
de" e "generosidade" (objeto de nossa pesquisa) serão aqueles que definem a moral. Quanto à ética, lembrando que nem todo projeto de "vida boa" merece esse nome, assumiremos a definição de Paul Ricoeur (1990): a perspectiva ética é a "perspectiva de uma vida boa, para e com outrem, em instituições justas" (p. 202). Essa definição de ética nos permite compreender sua amplitude: uma vida boa, em termos éticos, é consequiência de um sentido de felicidade que contemple o si mesmo e também o outro, objeto da moral, e completa-se em instituições em que um conteúdo moral esteja presente: a justiça.

Se empregamos essas definições de moral e de ética, é porque fazemos a hipótese de que as duas dimensões - dever e "vida boa" - são articuladas do ponto de vista psicológico. Fazemos a hipótese geral de que os deveres morais somente serão intimamente legitimados e, portanto, inspirarão as ações dos indivíduos para os quais eles são partes integrantes de uma "vida boa", por aqueles, portanto, que possuem uma ética, como assim definida por Ricoeur (1990).

Tal hipótese visa a equacionar um problema que tem desafiado a psicologia moral: a fonte energética da ação moral. Sabe-se que a maioria das pesquisas de psicologia moral tem focado a dimensão intelectual da moralidade. Sabe-se muito, desde o trabalho pioneiro de Piaget (1932/1994), sobre características do juízo moral e seu desenvolvimento, mas sabe-se muito menos sobre a dimensão afetiva da moralidade. É claro que embora a razão seja condição necessária à ação moral (e outras), ela não é condição suficiente. A razão, diria Taylor (1998), pode retificar os sentimentos, mas não pode substituir a intuição. De fato, amar o bem não se traduz em imitar a ordem, mas senti-lo enquanto impulsão ou completude. Há, portanto, um desejo ou um querer fazer que nos leva a agir moralmente.

Ora, qual a fonte energética desse "querer" singular que é o dever? Para responder a essa pergunta, colocamo-nos na perspectiva teórica que pensa a relação entre a moral e o "eu" (self). Encontra-se tal relação em alguns filósofos como Taylor (1998), para quem o Bem e o "eu" se interpenetram de forma inextricável: "nós somos nós na medida em que nós nos colocamos num certo espaço de questões, quando nos procuramos e encontramos uma orientação para o bem" (p. 55). Tugendhat (1999) fala em pertencimento a uma moral; Savater (2002) relaciona moral e amor próprio e, finalmente, Ricoeur $(1990,1993)$ procura dar um lugar à auto-estima, no que o vimos chamar de perspectiva ética.

Na psicologia, encontramos referências à tal relação em alguns autores. Temos, por exemplo, a abordagem de Flanagan (1996), que elabora a hipótese de que "as variações de auto-conceito e dos ideais intrapessoais acarretam uma grande diferença no que é notado, nas emoções, na maneira como expressamos e agimos, e também na maneira como dirigimos nossa vida". Outro exemplo encontra-se no trabalho de educação moral de Puig (1996), cujo livro intitulado "Personalidade Moral" foi escrito para analisar as relações entre identidade e opções éticas e morais. Escreve ele que "é precisamente nesse espaço da identidade que se buscam formas de vida boa e feliz, que surgem os nutrientes com os quais trabalhará o ethos dialógico, que aparecem o desacordo e a crítica, que se realizam as criações morais" (Puig, 1996, p. 134). Falemos ainda da perspectiva adotada por Colby e Damon (1993), que batizam de construção do moral self. Para eles, as pessoas que agem moralmente, notadamente as de vida moral exemplar, são pessoas que "unem a moralidade e o 'eu' numa proporção maior do que as outras" (p. 151). Blasi (1995) vai na mesma direção quando afirma que "em termos puramente conceituais, parece possível que o mais alto nível de integração moral esteja realizado quando a compreensão e o interesse morais fazem parte do autoconceito" (Blasi, 1995, p. 232). La Taille (2002), conceituando o "eu" como conjunto de representações de si, sendo elas necessariamente valores e cada indivíduo naturalmente motivado em ver a si próprio por intermédio de representações de valor positivo, fala em "personalidade ética": os valores morais ocupam o centro de tais representações e, por conseguinte, levam a pessoa dotada a agir coerentemente com a moral.

Em suma, todas essas abordagens teóricas são coerentes com a hipótese que guiou nossa pesquisa, a saber: há uma relação entre os valores éticos associados às representações de si e a qualidade dos juízos morais. E são também coerentes com a outra formulação que propusemos dessa mesma hipótese: os deveres morais somente serão intimamente legitimados e, portanto, inspirarão as ações dos indivíduos para os quais eles são partes integrantes de uma "vida boa", por aqueles que possuem uma ética, como assim definida por Ricoeur (1990) e que, portanto, tem um sentido para a vida que leve em conta o si mesmo e o outro.

Vimos que a pergunta que inspira a ética é "que vida eu quero viver?" Vejamos que essa pergunta implica outra, relacionada ao eu, "quem eu quero ser?", cuja formulação é correlata da primeira. Logo, as perspectivas adotadas pelos autores apresentados podem ser lidas à luz dos conceitos de moral e ética, assim como definidos no presente artigo.

Todavia, que saibamos, poucas pesquisas foram realizadas para dar sustentação empírica a essa forma de relacionar a moral e a ética, de articular valores morais ao "eu". Citamos anteriormente o estudo de Colby e Damon (1993), que consistiu em entrevistar pessoas de vida moral exemplar para verificar o quanto, para elas, era íntimo o vínculo entre agirem moralmente e serem elas mesmas. Há também os variados estudos sobre o sentimento de vergonha, sentimento este que incide sobre o "eu", que atestam uma relação entre a conquista da autonomia e a capacidade de experimentar a vergonha moral (aquela que incide sobre valores morais - La Taille, 2002). Nosso intento é de mostrar uma outra investigação empírica sobre o mesmo tema.

Falemos agora da concepção dessa pesquisa, que contém três estudos (Tognetta, 2006). Um primeiro que incide sobre as representações de si, portanto sobre a dimensão ética. Um segundo que incide sobre juízos diante de situações dilemas envolvendo questões de generosidade, que incide, portanto, sobre a dimensão moral. E um terceiro que consiste em cruzar os dados dos dois primeiros a fim de encontrar a suposta relação entre moral e ética.

Para o primeiro estudo, escolhemos tratar o tema da admiração. Em linhas gerais, pedimos a nossos sujeitos que dissessem o que admiram nas pessoas e o que acreditam que outras pessoas admiram neles próprios (ver detalhes no item Método). O tema da admiração relaciona-se diretamente com as representações de si e privilegia o caráter valorativo dessas (Dias, 2002). Com efeito, admirar características pessoais implica julgar como de grande valor tais qualidades. É certo que a palavra admiração pode ser empregada com um sentido um pouco diferente, o de espanto perante algo inesperado ou inusitado. Porém, tal não é o sentido mais usual (nossos 
sujeitos não se referiram a ele), que remete a virtudes, morais ou não. Pode-se admirar alguém por ser fisicamente belo, por cantar bem, eis exemplos de virtudes não morais. E pode-se admirá-lo por ser justo, honesto, corajoso, generoso, etc., eis virtudes morais. Ora, quisemos justamente verificar que tipo de virtudes nossos sujeitos evocavam quando lhes era pedido para falar de admiração. Seriam virtudes que chamamos de individualistas, nas quais não há a inclusão de outrem (ser bonito, por exemplo)? Seriam virtudes estereotipadas, que correspondem a traços de caráter convencionais (como a boa educação, a simpatia)? Ou seriam virtudes morais, como a justiça, a generosidade? Dito de maneira diferente, buscamos saber se os ideais de "eu" seriam condizentes com a ética assim como a definimos ou estranhos a ela. Falta explicar a razão de perguntarmos a nossos sujeitos o que admiram nos outros e o que os outros admiram neles. Por que não perguntar, de chofre, o que admiram neles mesmos? Por um lado, julgamos que poderia haver um certo constrangimento, uma certa invasão de intimidade ao fazer uma pergunta tão direta. Por outro lado, tememos que os sujeitos, por uma mistura de amor próprio e modéstia, nos dessem, sobretudo, respostas estereotipadas. Enfim, tememos obter respostas pouco representativas. Em compensação, ao perguntar o que admiravam nas outras pessoas, pressupomos maior sinceridade dos sujeitos, e também maior trabalho de descentração por parte deles. E ao perguntar, em seguida, sobre que qualidade eles pensavam ser admiradas por outrem, pressupomos também a mesma descentração, a tomada de consciência de si por intermédio do olhar alheio.

O segundo estudo incidiu sobre juízos morais a respeito da generosidade. Para tal, empregamos três dilemas (ver texto no item Método e Resultados) que opunham opções por ações generosas (que contemplam uma necessidade alheia) a 1) realizar um forte desejo pessoal, 2) ordem contrária de uma figura de autoridade, 3) pressões contrárias do grupo social. Mais duas histórias foram empregadas para saber se os sujeitos mais se indignam com cenas de não generosidade ou com perdas próprias. Nosso intento foi o de verificar a força da legitimação moral da generosidade perante os outros valores elencados.

O terceiro e último estudo consistiu em verificar a nossa hipótese: se for correta, é de se esperar que os sujeitos que mais virtudes morais admiram como características do "eu" mais legitimação apresentam em relação a ações que envolvem a generosidade. Ou seja, as opções por ações morais (moral) apresentariam correlação com os valores presentes nas representações de si (perspectiva ética). É claro que não pudemos observar as ações que efetivamente nossos sujeitos realizariam se passassem por situações como as propostas. Mas acreditamos que, indiretamente, obtivemos indícios dessas escolhas.

\section{Método}

Participaram dos três estudos, 75 estudantes de 12 a 15 anos de escolas particulares da cidade de Campinas. São meninos e meninas, de nível socioeconômico médio-alto, que foram escolhidos aleatoriamente. A escolha da idade de nossos participantes, na adolescência ou entrando nela, deu-se em função da integração dos valores à personalidade existente nessa fase. Aos participantes dessa pesquisa foi solicitado que respondessem a um questionário escrito, dividido em duas partes, referentes aos estudos 1 e 2 .

\section{Estudo 1}

Duas perguntas foram feitas: 1) "O que uma pessoa faz que possa merecer sua admiração?" e 2) "O que as pessoas podem admirar em você?"

\section{Estudo 2}

Foram colocadas cinco histórias versando sobre generosidade, que resumimos a seguir. Na primeira história, há um jogo de forças entre ser generoso ou cumprir um forte desejo pessoal. Um menino (Paulo) decide não emprestar a outro menino, Michel, um brinquedo de que gosta muito e com o qual tem muita vontade de brincar. Pergunta-se aos sujeitos:

Você acha que Paulo agiu bem? Por quê?

Como ele se sentiu agindo dessa forma? Por quê?

Em sua opinião, quem você acha que se sentiu mais triste? Michel, que não pôde ter o brinquedo, ou Paulo, por não ter emprestado?

A segunda história apresenta a contraposição entre ser generoso ou obedecer a uma autoridade: duas irmãs, Isabelle e Anne, excelentes em subir em árvores, mas proibidas pelo pai de fazê-lo, ouvem uma terceira menina lhes pedir para salvar um gato que está no topo de uma árvore. Ana resolve ajudar, mas Isabelle resolve obedecer ao pai. Perguntas aos sujeitos:

Quem você acha que fez uma ação mais admirável? Isabelle ou Anne? Por quê?

Quem se sentiu mais triste: Anne, que desobedeceu ao pai e pegou o gatinho, ou Isabelle, que se negou a pegar o gatinho para obedecer ao pai? Por quê?

A terceira história opõe a obediência à recusa de um ato de humilhação. Um menino (João) obedece ao chefe de seu grupo que o manda, sob pena de excluí-lo do grupo em caso de recusa, humilhar um colega (David). João insulta David. Perguntas:

\section{João agiu bem? Por quê? \\ Como você acha que João se sentiu agindo assim? Por quê? \\ Quem você acha que se sentiu pior: David, o garoto a quem João humilhou, ou o próprio João. Por quê?}

A quarta história, que retoma a anterior, coloca a questão da força dos sentimentos. O que deixa Antônio com mais raiva: ter perdido uma coisa de que gostava muito ou ter assistido à humilhação de David? Perguntas:

\section{O que deixa Antonio com mais raiva:}

Ter perdido numa aposta algo que gostava muito ou ver o menino sendo humilhado por João. Por quê?

A quinta história também se refere à humilhação. O que deixa Pierre com mais raiva: perder um concurso ou saber que seu colega apanhou do pai? Perguntas: 
O que deixa Pierre com mais raiva: não ter ganhado uma bicicleta nova no concurso ou saber que seu amigo está machucado por ter apanhado de seu pai. Por quê?

\section{Estudo 3}

O estudo 3 consiste no cruzamento dos dados dos dois primeiros estudos em vista de verificar a hipótese central do presente artigo: existe uma correspondência entre as imagens que os sujeitos têm de si e seus julgamentos por generosidade. Para tanto, empregamos testes estatísticos: teste Exato de Fisher, teste Qui-quadrado, teste Stuart-Maxwell e a Análise de Correspondência Múltipla.

\section{Resultados}

\section{Estudo 1}

Comecemos por lembrar as categorias que empregamos para classificar as respostas. Chamamos de Categoria $\mathrm{AE}^{2}$ aquela das repostas individualistas (não inclusão de outrem, nem referência à moral, nem referência a caráter). Exemplo para a admiração do outro: "essa pessoa faz com que a coisa que elaborou chame a atenção do outro, ou seja, que ela faça uma coisa muito bonita e elaborada para que todos gostem, admirem o que fez". Exemplo para a admiração de si: "Eu sou muito bem humorado, sou muito otimista. Na escola, sou muito bom goleiro; os professores se espantam com minha 'experiência'”.

Chamamos de Categoria BE aquela das respostas que chamamos de estereotipadas. Elas se distinguem das repostas da Categoria A por haver referência a traços de caráter, no entanto, com distinções bastante estereotipadas que não explicitam um caráter verdadeiramente ético. Exemplo de admiração do outro: "quando uma pessoa consegue uma coisa com a qual ela sempre sonhou, porque ela lutou por aquilo". Exemplo de admiração de si: "eu me acho um cara bacana, bonito, mas muito nervoso, gosto de ser simpático e gentil". Ou ainda, "do meu jeito carinhoso e engraçado. E do meu lindo sorriso".

E chamamos de Categoria CE aquela das repostas que remetem a virtudes morais que apontam para uma personalidade ética. Essas respostas evidenciam um olhar atento de nossos interlocutores a valores como a solidariedade, a honestidade, a fidelidade, a justiça. Exemplo de admiração do outro: "eu admiro quando uma pessoa fala a verdade, é sincera, tenta superar as suas dificuldades e assume o que faz e que, às vezes, admite que errou. Admiro isso, pois essas são qualidades que uma pessoa pode ter e essas pessoas são boas". Exemplo de admiração de si: "as ações que eu tenho que as pessoas podem admirar é respeitar todos, não me importando com as diferenças; ajudar, quando possível um amigo, um parente que esteja passando por alguma dificuldade apresentada".

Isso posto, vamos aos dados, começando pela freqüência das três categorias para a admiração de outrem (Tabela 1).

Observando a tabela, podemos considerar que pouco mais da metade de nossos sujeitos apresenta, em suas respostas,

2 As Categorias A, B e C do Estudo 1 são sucedidas pela letra $\mathrm{E}$ pois se referem à Ética.
Tabela 1. Admiração de outrem: Quantidade de respostas em cada categoria.

\begin{tabular}{ccc}
\hline Categorias & Freqüência & Percentual \\
\hline $\mathrm{AE}$ & 12 & 16.00 \\
$\mathrm{BE}$ & 24 & 32.00 \\
$\mathrm{CE}$ & 39 & 52.00 \\
\hline
\end{tabular}

um conteúdo ético quanto ao que admiram. Apenas uma porcentagem pequena, $16 \%$, aponta para certo individualismo em suas respostas (categoria AE).

Na Tabela 2, podemos encontrar as porcentagens extraídas das respostas de nossos sujeitos quanto ao que as pessoas podem admirar neles.

Tabela 2. Admiração por si mesmo: quantidade de respostas em cada categoria.

\begin{tabular}{ccc}
\hline Categorias & Freqüiência & Percentual \\
\hline $\mathrm{AE}$ & 12 & 16.00 \\
$\mathrm{BE}$ & 28 & 37.33 \\
$\mathrm{CE}$ & 35 & 46.67 \\
\hline
\end{tabular}

Verifica-se que os números encontrados são semelhantes àqueles referentes à admiração de outrem. Voltaremos a esses dados em nossa discussão geral.

De posse de tais dados, fizemo-nos então uma pergunta crucial: poderíamos encontrar uma "conservação de valores" entre os aspectos admiráveis que compõem as imagens de si e as ações admiráveis nos outros? Nosso intuito foi verificar se os participantes de nossa pesquisa teriam ou não a mesma classificação de suas respostas nas categorias $\mathrm{AE}, \mathrm{BE}, \mathrm{CE}$, nas duas perguntas sobre a admiração, para tal, unimos essas respostas visando encontrar sua conservação nas categorias descritas. Essa ação nos permitiu encontrar uma melhor tradução dos sistemas identificatórios que compõem o que chamamos de imagens de si. Para saber se o estabelecimento das "respostas que se conservam" daria conta de responder a essa demanda e se esse seria um bom instrumento para ser utilizado, aplicamos um teste estatístico - Teste Stuart-Maxwell que nos permitiu afirmar tal proposição. Esse teste compara as distribuições das respostas aos dois questionamentos e aponta um nível de significância (p-valor) de 0,6564. Na Tabela 3, encontram-se os percentuais de respostas conservadas quanto ao que admiram.

Tabela 3. Conservação da admiração a si e a outrem: Quantidade de respostas em cada categoria.

\begin{tabular}{ccc}
\hline Categorias & Frequiência & Percentual \\
\hline $\mathrm{AE}$ & 10 & 13.33 \\
$\mathrm{BE}$ & 16 & 21.33 \\
$\mathrm{CE}$ & 27 & 36.00 \\
$\mathrm{NC} *$ & 22 & 29.33 \\
\hline
\end{tabular}

$p=0,6564$ (teste de Stuart-Maxwuell)

"Não conservadores.

Pela tabela, temos uma freqüência crescente dos sujeitos que conservam a mesma categoria para as duas perguntas sobre a admiração: notemos como os sujeitos da categoria CE cuja admiração é ao caráter ético são em maior número. Trataremos disso brevemente. Pela tabela também constatamos que apenas $29.33 \%$ das respostas não conservam o que nos garante um bom percentual de conservação. 


\section{Estudo 2}

As respostas das perguntas realizadas em cada dilema relativas ao dever e aos sentimentos dos personagens nos dilemas 1, 2 e 3 foram categorizadas pensando-se numa evolução que pudesse mostrar desde a ausência da generosidade (categoria $\mathrm{AM}^{3}$ ) até quando essa virtude fosse apresentada como sendo uma disposição julgada necessária pelos sujeitos (categoria DM). Da mesma forma, encontramos categorias que elucidam desde o fato de não estarem sensíveis aos sentimentos dos personagens (categoria $\mathrm{AM}$ ) até quando os sentimentos dos envolvidos correspondem a sentimentos morais como arrependimento, vergonha e culpa, quando tratamos das respostas que preconizam como os personagens se sentiram (categoria DM). Quanto às respostas dos dilemas 5 e 6 , essas foram, igualmente, distribuídas em categorias de AM a DM. Há outras, intermediárias, BM e $\mathrm{CM}$, contudo, optamos por trabalhar com os extremos, visto que nosso interesse é por encontrar respostas que não vão em direção à generosidade e aquelas que vão claramente à essa virtude.

Deixamos de apresentar os resultados parciais obtidos na discussão de cada pergunta de cada um de nossos cinco dilemas para não nos estender, visto que o maior objetivo, por ora, é comprovar nossa hipótese da correspondência entre ética e moral. Contudo, ainda que este estudo não seja para nós o mais importante e o que se destina o atual artigo, vejamos que seus resultados nos instigam a algumas constatações interessantes quando analisamos em contraposição às categorias AM e DM (ainda que encontremos as intermediárias BM e CM ou BM quando apenas tivemos AM, BM, CM) dos dilemas 1, 2 e 3. Para tal análise, apresentamos a Tabela 4, que aponta os percentuais de respostas dadas para a primeira pergunta de cada dilema relativas a considerar a necessidade da generosidade .

Se na perspectiva deontológica, ou, em outras palavras, quando questionamos sobre a necessidade da ação generosa perguntando se o personagem não generoso nos diferentes dilemas agira bem, a maioria das respostas encontrava-se na

Tabela 4. Percentual de respostas nas categorias AM e DM em comparação para os dilemas 1, 2 e 3, numa perspectiva deontológica.

\begin{tabular}{cccc}
\hline Dilema & Questão & Categoria AM & Categoria DM \\
\hline 1 & 1 & 10.67 & 65.33 \\
2 & 1 & 17.33 & 70.67 \\
3 & 1 & 2.67 & 57.33 \\
\hline
\end{tabular}

Tabela 5. Percentual de respostas nas categorias AM e DM em comparação para os dilemas 1,2 e 3 , numa perspectiva afetiva.

\begin{tabular}{cccc}
\hline Dilema & Questão & Categoria AM & Categoria DM \\
\hline 1 & 2 & 38.67 & 37.33 \\
2 & 3 & 45.33 & 32.00 \\
3 & 2 & 13.33 & 50.67 \\
& 2 & 13.33 & 25.33 \\
\hline
\end{tabular}

3 As categorias $\mathrm{A}, \mathrm{B}, \mathrm{C}, \mathrm{D}$ do Estudo 2 são sucedidas de $\mathrm{M}$ pois se referem à Moral. categoria DM, vamos ver que, quando se trata de atribuição de sentimentos, ou seja, quando nossos sujeitos poderiam ou não estar sensíveis aos sentimentos dos personagens, não encontramos a mesma direção. A Tabela 5 atesta tais conclusões:

Discutiremos esses resultados mais adiante. Por ora, notemos que os percentuais de respostas em que os participantes estão sensíveis aos sentimentos dos personagens não são tão diferentes entre seus extremos.

\section{Estudo 3}

Para então verificarmos se existiria uma correspondência entre Ética e Moral, fizemos um cruzamento das respostas de conservação do primeiro estudo (ética) e daquelas sobre os dilemas de generosidade do segundo estudo (moral). Procuramos encontrar as evidências de associação entre cada pergunta de cada um dos dilemas e as respostas sobre a admiração que foram dadas pelos sujeitos, e para comprovar essa correspondência, aplicamos o teste Exato de Fisher em cada uma dessas associações.

Poderíamos encontrar, entre os sujeitos cujas respostas foram caracterizadas como categoria A (conteúdos individualistas) quanto ao que admiram, mais respostas nas categorias menos evoluídas da moral quando da discussão dos dilemas? Nessa mesma perspectiva, onde estariam as respostas mais evoluídas em termos de conteúdo moral quanto aos dilemas: teriam sido dadas pelos sujeitos cujas imagens de si se relacionam ao caráter ético?As respostas são afirmativas. Vejamos que há algumas diferenças quando analisamos as correspondências entre as respostas que se referem à generosidade como um dever e àquelas que traduzem os sentimentos evidenciados nas situações em que tal virtude está ausente. Com a aplicação do teste exato de Fisher, pudemos constatar a evidência da associação entre ética e moral em algumas respostas, e não em outras. Algumas constatações foram possíveis: em três das questões sobre os sentimentos, questão 3 do dilema $1(p=0,0475)$, questão 2 do dilema 2 $(p=0,0032)$ e questão 3 do dilema $3(p=0,0512)$; tivemos a evidência de que sujeitos individualistas tendem a estar menos atentos aos sentimentos dos personagens na ausência da generosidade, contrariamente ao que acontece entre os sujeitos éticos. Quanto às respostas relativas ao dever, apenas em uma das questões - questão 1 do dilema $2(p=0,0454)$ - houve a evidência da correspondência entre ética e moral, o que nos indica que os sujeitos individualistas poderiam também julgar a generosidade como uma necessidade.

Para saber se haveria, de fato, diferenças significativas no montante de respostas dadas por esses sujeitos, tivemos outra indagação: será que, se juntássemos todas as respostas para todos os dilemas (1 a 5), poderíamos encontrar as mesmas correspondências? A resposta a essa pergunta nos foi possível pela aplicação da Análise de Correspondência Múltipla. Esta tem por objetivo identificar padrões de respostas em cada grupo (em nosso caso, em cada categoria de respostas) e, a partir do mapa traçado, identificar, por exemplo, se as respostas das categorias mais evoluídas, como a categoria DM de nossos dilemas, estariam integradas ao que se chama de "grupo de interesse", em nosso caso, aos sujeitos cujas imagens se referem ao caráter ético, CE.

Considerando as duas primeiras dimensões para análise dos dados num plano, temos $82,7 \%$ da variação total dos 


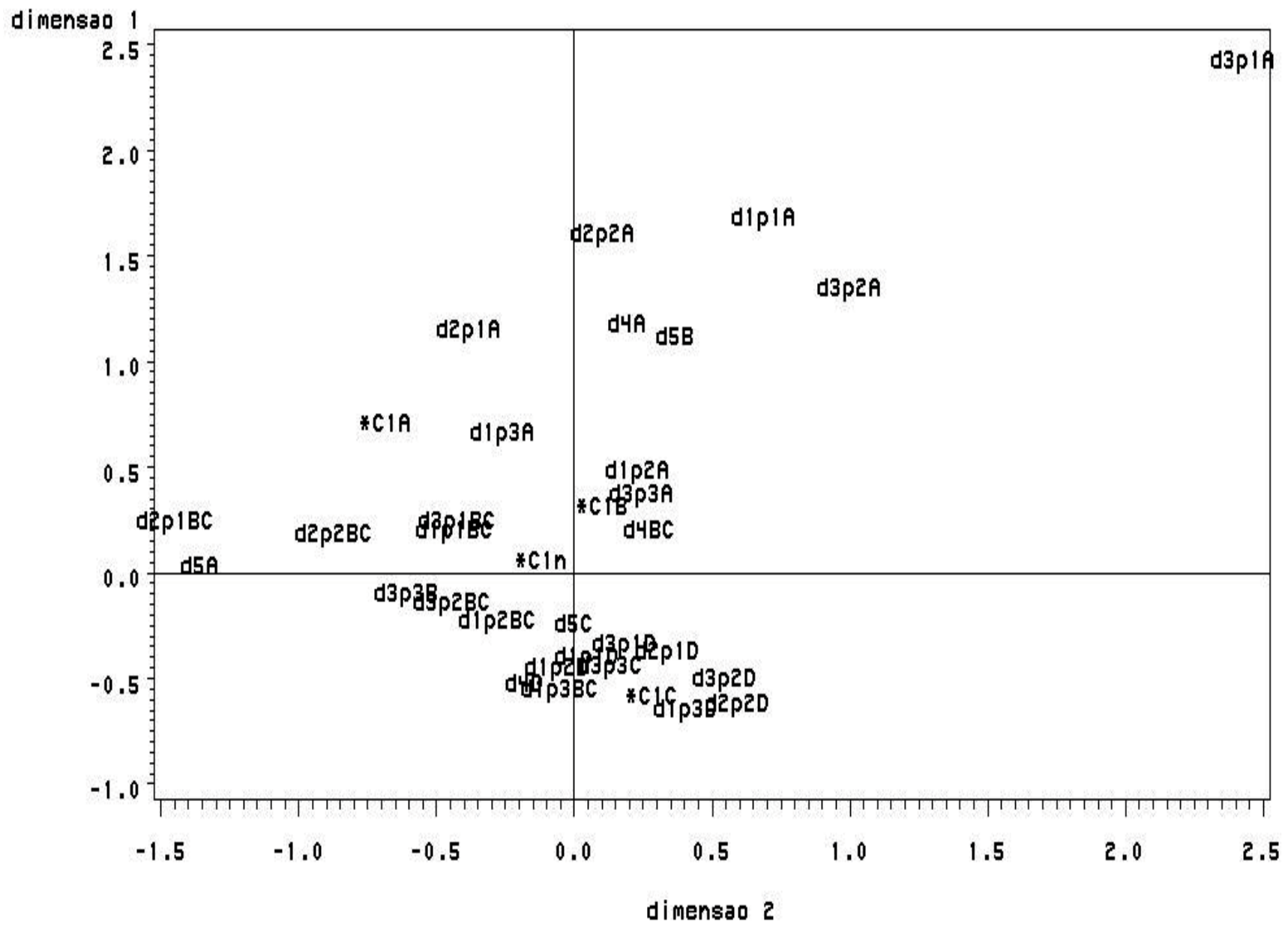

Figura 1. Mapa da Análise de Correspondência Múltipla para os dilemas, no grupo de brasileiros, utilizando como variável suplementar a conservação da admiração.

dados explicada. Algumas explicações são necessárias para interpretação do mapa. Nele, foram integradas todas as respostas para cada uma das perguntas de cada dilema. É possível distingui-las da seguinte forma: D1p1A - Dilema 1, pergunta 1, categoria A; D1p1BC-Dilema 1, pergunta 1, categorias agregadas B e C; D1 p1D - Dilema 1, pergunta 1, categoria D.

Só para que nos lembremos, o dilema 1 corresponde ao dilema de Paulo e Michel e coloca em jogo o agir generosamente, emprestando um objeto novo para o outro. A pergunta 1 se refere à perspectiva de julgar o agir bem ou agir mal. Para tal pergunta, obtivemos a categoria A, que foi por nós considerada menos evoluída em termos de conteúdos morais, pois negava a ação generosa. As categorias B e C são tomadas aqui como intermediárias entre o agir bem em não ser generoso e a ação julgada necessária por conteúdos morais mais distintos, que foram englobados, por sua vez, na categoria $\mathrm{D}$.

Da mesma forma, temos as perguntas 2 e 3 do dilema 1 , que se referem aos sentimentos dos personagens envolvidos: D1p2A - Dilema 1, pergunta 2, categoria A; D1p2BC - Dilema 1, pergunta 2, categorias agregadas BC; D1p2D - Dilema 1, pergunta 2 Categoria D.
Assim, sucessivamente, todos os dilemas com as respostas para todas as suas perguntas e suas conseqüentes categorias estão sobrepostos no mapa em questão. No mapa, ainda poderemos encontrar as siglas $\mathrm{C} 1 \mathrm{~A}$, para conservação das respostas de admiração a conteúdos individualistas, C1B, para conservação das respostas de admiração a conteúdos de caráter moral, ainda que demonstrem os estereótipos sociais, $\mathrm{C} 1 \mathrm{C}$, para conservação das respostas de admiração a conteúdos de caráter ético e, finalmente, $\mathrm{C} 1 \mathrm{n}$, para as respostas que não conservaram um mesmo valor e, portanto, não se encontram na mesma categoria nas duas formas de admiração por si e pelo outro.

A partir de tais orientações, vejamos o que pudemos encontrar como resposta a nosso problema de pesquisa: haverá correspondência entre as imagens de si e os dilemas morais?

As categorias mais evoluídas (que anteriormente chamamos de DM) dos dilemas 1, 2, 3 (representadas no mapa como D1p2D e D1p3D, D2p2D, D3p2D e D3p3D), para as questões que se remetiam a "estar sensível" aos sentimentos dos personagens e dos dilemas 1 e 2 (D1p1D e D2p1D no mapa), quanto às questões que levariam a pensar a generosidade como necessidade, estão próximas às respostas 
daqueles que conservam a admiração a conteúdos éticos (C1C no mapa). Ao mesmo tempo, as categorias menos evoluídas (que anteriormente chamamos de AM) dos dilemas 1 e 2 (D1p2A, D1p3A e D2p2A no mapa) para as questões que tratavam dos sentimentos dos personagens e a categoria intermediária (representadas no mapa por D4p1BC - chamadas anteriormente de $\mathrm{BCM}$ ) do dilema 4 estão próximas às respostas daqueles que conservam a admiração a conteúdos estereotipados (representados por C1B no mapa) e, ainda, as categorias menos evoluídas (AM) do dilema 2 (D2p1A no mapa), sobre a questão da necessidade da ação generosa, e do dilema 1 (D1p2A no mapa), sobre os sentimentos dos envolvidos, estão próximas àqueles cuja admiração evidencia conteúdos individualistas (C1A no mapa).

\section{Discussão}

Nossos dois primeiros estudos foram apresentados objetivando apontar os dados necessários à comprovação de nossa hipótese. Contudo, os resultados desses estudos parecem ser também importantes para a Psicologia Moral.

No primeiro estudo, a mostra que tivemos sobre o que adolescentes de 12 a 15 anos admiram pode servir de alento àqueles que costumeiramente apontam para a juventude atual como uma geração sem valores. Esses adolescentes ainda concebem conteúdos éticos como admiráveis. Por certo, essa constatação não exime o fato de que há outros valores presentes na geração atual que se distanciam da ética. Porém, nossos dados revelam uma visão otimista de que é possível que os jovens possam integrar as virtudes morais ao que admiram, embora haja um bombardeio de contra-virtudes em sua formação atual. Em uma pesquisa anterior (La Taille, 2006b), encontramos dados similares quando questionamos 5.000 jovens da cidade de São Paulo: a moral (59\%) ainda é item mais importante para a sociedade entre outros, como política $(10,7 \%)$, religião $(10,2 \%)$, ciência $(15,3 \%)$ e arte $(4,7 \%)$.

Há também outro dado importante neste estudo. Se nos voltarmos à conservação das respostas obtidas às duas formas de admiração, podemos nos indagar: entre quais sujeitos é maior tal conservação? Interessantemente, a resposta para essa pergunta nos remete a Piaget (1932/1994), quando o autor reitera que a moral é conservação de valores. Ora, verificamos justamente que aqueles que admiram conteúdos éticos são os que se mantêm atentos a tais valores.

Vejamos que este primeiro estudo apresentado pôde cumprir a tarefa de revelar uma possível perspectiva ética nas representações de si, mas ainda não cumpriu nosso maior objetivo: afinal, existirá uma correspondência entre essa perspectiva ética nas representações de si e conteúdos de natureza moral nos julgamentos a situações que envolvam a generosidade? No entanto, para responder a essa instigante pergunta foi preciso realizar um segundo estudo, no qual se puderam constatar os julgamentos de nossos sujeitos a um conteúdo moral.

Os resultados de nosso segundo estudo atestaram uma diferença em termos de julgar a necessidade do ato generoso e estar sensível aos sentimentos dos envolvidos. Vimos que essa primeira perspectiva foi freqüentemente tomada por nossos participantes, mas não foi o que aconteceu quando se tratava de elucidar sentimentos morais como honra, vergo- nha, arrependimento ou culpa na ausência da generosidade. A explicação para esse fato pode talvez ser encontrada na oposição entre heteronomia e autonomia. Pela heteronomia, ou seja, pela reprodução verbal de conteúdos morais ouvidos da boca de autoridades ou simplesmente considerados como socialmente aceitáveis, é possível entender a maior presença de discursos que legitimam mais a generosidade do que a perspectiva individualista. Mesmo no dilema 2, que opõe ordem de um pai a uma opção de ação generosa, o fato de tal opção ser a mais lembrada não contradiz nossa explicação, pois sujeitos adolescentes costumam já ter superado a obediência à figura de autoridade parentais (Piaget, 1932/1994). Mas isso não significa dizer que não admiram a outras figuras de autoridade, a do grupo, por exemplo. Em compensação, a atribuição de sentimentos depende menos das influências de coação de figuras de autoridade, do que de juízos autônomos, como o demonstram as pesquisas de Arsenio e Lover (1996), de Nunner-Winkler e Sodian (1988), de Lourenço (1997) e La Taille (2006a). Com efeito, as pesquisas sobre o que foi chamado de "happy victimiser" mostraram que as crianças pré-operatórias atribuem sentimentos positivos a agressores, embora condenem moralmente seus atos. Logo, não há necessariamente correspondência entre juízo moral e atribuição moral de sentimentos, sendo que tal correspondência tende a se impor entre os sujeitos autônomos.

Ora, os resultados do estudo 3 tendem a mostrar que levar moralmente em conta os sentimento alheios não é capacidade dos que julgam a generosidade correta, mas sim dos que parecem ter assimilado às suas próprias identidades uma perspectiva ética, ou seja, daqueles para quem a "vida boa" inclui virtudes morais. Piaget (1932/1994) já dizia que a autonomia implica um investimento da própria personalidade na moral e, inversamente, um enraizamento desta na identidade. Nossos resultados apontam para a verossimilhança dessa hipótese.

Pudemos, com efeito, constatar que, para os sujeitos cuja admiração corresponde a conteúdos individualistas, quando tratamos de evidenciar os sentimentos morais, nos três dilemas, a categoria AM (inferior) teve sempre maior percentual que DM (superior), em que tais sentimentos são elucidados. Aqueles cuja admiração é ainda em BE, pelos estereótipos sociais, oscilaram ora nada sensíveis aos sentimentos presentes na ausência de generosidade ora comovidos pela vergonha, pela indignação ou arrependimento.

Todavia, foi entre aqueles cuja perspectiva é ética que encontramos os maiores percentuais na categoria DM (voltemos aos resultados da análise de correspondência): estes estavam sempre sensíveis aos sentimentos dos personagens e apresentavam aqueles denotados sentimentos morais. Como vimos, quando se tratava de constatar a necessidade da generosidade, nossos sujeitos, admirando quer sejam conteúdos individualistas (AE), ou estereotipados (BE) ou ainda conteúdos éticos (CE), poderiam também estar igualmente dispostos. Porém, muito mais do que julgar pela necessidade ou pelo dever, aqueles cuja personalidade pudemos agregar o adjetivo ética, apresentaram-se muito mais propensos ao reconhecimento dos sentimentos envolvidos no ato generoso.

Para finalizar, voltemos à hipótese geral que inspirou o presente estudo: os deveres morais somente serão intimamente legitimados e, portanto, inspirarão as ações dos indivíduos para os quais eles são partes integrantes de uma "vida boa", 


\section{R. P. Tognetta \& Y. Taille}

por aqueles, portanto, que possuem uma ética, como assim definida por Ricoeur (1990). Tal hipótese não foi confirmada se nos fixarmos apenas nos juízos morais: julgam ser corretos atos de generosidade pessoas que interpretam "vida boa" e identidade seja por intermédio de virtudes morais, seja por outras. Em compensação, ela se mostra correta no que tange à atribuição de sentimentos morais, atribuição esta que vimos ser característica da autonomia. Parece, portanto, realmente haver relação entre moral e ética, fato que pensamos ser relevante para os estudos de Psicologia Moral e para as perspectivas de educação moral e formação ética. Mas, é evidente, mais pesquisas devem ser feitas para aprofundar as características dessa relação que articula 'vida boa' e 'dever'.

\section{Referências}

Arsenio, W. \& Lover, A. (1996). Children's conception of sociomoral affect: happy victimizers, mixed emotions, and other expentancies. Em M. Killer \& D. Hart (Orgs.), Morality in everyday life (pp. 87-128). Cambridge: Cambridge University Press.

Blasi, A. (1995). Moral understanding and the moral personality: the process of moral integration. Em W. M. Kurtines \& J. L. Gewirtz (Orgs.), Moral development: an introduction (pp. 229-154). London, Allyn and Bacon.

Blondel, E. (2000). Le problème moral. Paris: PUF.

Colby, A. \& Damon, W (1993). The uniting of self and morality in the development of extraordinary moral commitment. Em G. C. Noam \& E. Wren (Orgs.), The Moral Self (pp. 149-174). Cambridge: The Mit Press.

Comte-Sponville, A (1999). Pequeno tratado das grandes virtudes. São Paulo: Martins Fontes.

Dias, A. C. F. (2002). Estudo psicológico sobre o lugar das virtudes no universo moral aos 7 anos de idade: as crianças da 1a. Série discutem coragem e generosidade. Dissertação de Mestrado, Universidade de São Paulo, São Paulo.

Flanagan, O. (1996). Psychologie morale et éthique. Paris: PUF.
Harckot-de-la Taille, E. \& La Taille, Y. (2006). Valores dos jovens de São Paulo. Em: La Taille, Y. Moral e ética-dimensões intelectuais e afetivas. Porto Alegre: Artmed.

La Taille, Y. (2002). Vergonha: a ferida moral. São Paulo: Ed. Vozes.

La Taille, Y. (2006a). A importância da generosidade no início da gênese da moralidade na criança. Psicologia: Reflexão e Crítica, 19(01), 9-17.

La Taille, Y. (2006b). Ética e Moral: dimensões intelectuais e afetivas. Porto Alegre: Artmed.

Lourenço, O. (1997). Children's attribution of moral emotions to victimizers: some data, doubts ans suggestions. British Journal on Development Psychology, 15, 425-438

Nunner-Winkler, G. \& Sodian, B. (1988). Children's understanding of moral emotions. Child Development, 59, 1323-1338.

Piaget, J. (1994). O juízo moral na criança. São Paulo: Summus Editorial. (Trabalho original publicado em 1932)

Puig, J. M. (1996). A construção da personalidade moral. São Paulo: Editora Ática.

Ricoeur, P. (1990). Soi-même comme un autre. Paris: Éditions du Seuil.

Ricoeur, P. (1993) Le "soi" digne d'estime et de respect. Em: Audard, C. (Org.). Le respect. De l'estime à la déférence: une question de limite. Saint-Armand: Éditions Autrement, série Morales.

Savater, F. (2002). Ética para meu filho. São Paulo: Martins Fontes.

Taylor. C. (1998). Les sources du moi. Paris: Éditions du Seuil.

Tognetta, L. R. P. (2006). Sentimentos e virtudes: um estudo sobre a generosidade ligada às representações de si. Tese de doutorado, Universidade de São Paulo, São Paulo.

Tugendhat, E. (1999). Lições sobre ética. Petrópolis: Vozes.

Williams, B. (1990). L'Ethique et les limites de la philosophie. Paris: Gallimard.

Recebido em 10.03.2007

Primeira decisão editorial em 13.08.2007

Versão final em 13.09.2007

Aceito em 03.03.2008 